\title{
Performance and Variability Trade-off With Gate-to-Source/Drain Overlap Length
}

\author{
B. P. Harish and Navakanta Bhat ${ }^{1}$ \\ Department of Electrical Engineering, University Visvesvaraya College of Engineering, Bangalore University, Bangalore, \\ ${ }^{1}$ Department of Electrical Communication Engineering, Indian Institute of Science, Bangalore, Karnataka, India
}

\begin{abstract}
The impact of gate-to-source/drain overlap length on performance and variability of $65 \mathrm{~nm}$ CMOS is presented. The device and circuit variability is investigated as a function of three significant process parameters, namely gate length, gate oxide thickness, and halo dose. The comparison is made with three different values of gate-to-source/drain overlap length namely $5 \mathrm{~nm}, 0 \mathrm{~nm}$, and $-5 \mathrm{~nm}$ and at two different leakage currents of $10 \mathrm{nA}$ and $100 \mathrm{nA}$. The WorstCase-Analysis approach is used to study the inverter delay fluctuations at the process corners. The drive current of the device for device robustness and stage delay of an inverter for circuit robustness are taken as performance metrics. The design trade-off between performance and variability is demonstrated both at the device level and circuit level. It is shown that larger overlap length leads to better performance, while smaller overlap length results in better variability. Performance trades with variability as overlap length is varied. An optimal value of overlap length of $0 \mathrm{~nm}$ is recommended at $65 \mathrm{~nm}$ gate length, for a reasonable combination of performance and variability.
\end{abstract}

\section{Keywords:}

Drive current, Inverter stage delay, Mixed mode simulations, Overlap length, Process sensitivity, Variability-aware device design.

\section{INTRODUCTION}

Parametric mismatch due to process variations is emerging as a significant barrier for realizing acceptable levels of performance and yield in nanoscale CMOS technologies. Design for Manufacturability and Yield (DFM and DFY) have received much attention in nanoscale technologies. Parametric fluctuations have evolved from a typical high-precision analog circuit design issue to a serious performance and yield limiter in pursuit of giga-scale integration. One of the most important and difficult challenge confronting the semiconductor industry is the loss of predictability in the functional correctness and performance of nanometer scale integrated circuits. It is expected that performance variances, caused by this mismatch, in short-channel MOS circuits may, ultimately, introduce a limitation for device scaling in integrated circuits $[1,2]$. It has been shown that parametric mismatch forms a fundamental limit for realizing acceptable levels of performance and yield in nanoscale CMOS technologies and suggested for tighter control of conventional processes and development of improved device architectures[3]. For the technology to continue to advance along the Moore's curve, it is imperative to develop techniques to predict and to optimize the performance of ICs in the circuit design domain and to identify device structural parameters in the device design domain, in the presence of process variations. Thus, there is an urgent need to tighten the performance distribution of chips, both at the circuit design level and at the device design level, to achieve robust device/circuit performance, in the presence of process variations. There have been several works in the circuit design domain, reported in the literature, with regard to the accurate prediction of delay and power in the presence of process variations [4-9]. To mitigate the effects of parametric mismatch, improved device architectures are required to be developed. This paper attempts to address the variability issue at the device design level, by identifying a variability-aware device design parameter.

There exists a critical gate-to-source/drain overlap length below which the device hot electron reliability suffers and a maximum value above which gate-tosource/drain capacitance becomes large and an optimal tradeoff between device performance and characteristics is achieved with in this narrow margin, that is shrinking with scaling[10]. The interaction of overlap length with lateral doping abruptness and the consequent impact on device performance is shown, indicating the use of overlap spacer for device optimization[11]. Traditionally, a minimum gate-to-source/drain overlap length of about $20 \mathrm{~nm}$ was recommended at $0.25 \mu \mathrm{m}$ process, from the source/drain series resistance consideration, to prevent drive current degradation[12]. However, recently, it has been demonstrated that a gate-to-source/drain overlap length of $0 \mathrm{~nm}$ is preferred in the sub- $100 \mathrm{~nm}$ regime from the perspective of digital and analog circuit 
[Downloaded free from http://www.jr.ietejournals.org on Tuesday, September 11, 2012, IP: 14.139.128.14] || Click here to download free Android application for this journal

Harish BP and Bhat N: Performance and Variability Trade-off with Gate-to-source/Drain Overlap Length

performance[13]. Also, $0 \mathrm{~nm}$ overlap length devices have been shown to exhibit better hot carrier and gate oxide reliabilities, in terms of reduced peak electric fields near the drain and reduced gate leakage currents, respectively. The characteristics of MOS transistor with non-overlapped gate-to-source/drain region has been investigated and shown that they have better subthreshold slope and drain induced barrier lowering (DIBL) than those of overlapped structures[14]. In this work, we explore the efficacy of gate-to-source/drain overlap length as a variability-aware device design parameter.

We perform mixed-mode simulations, which bring the process-simulated devices directly into the netlist of the circuit, wherein both circuit and device equations are solved simultaneously. This technique is accurate as it does not involve SPICE parameter extraction, given that SPICE parameters may not capture the device behavior very accurately in the nanoscale regime[15]. Process/device simulation is considered appropriate to the study of process sensitivity as it enables the precise control of process variations that are difficult to achieve experimentally. A commercial Technology Computer Aided Design (TCAD) tool suite Sentaurus from Synopsys has been used for this study[16].

Section 2 describes the simulation methodology. While Section 3 presents the process sensitivity at the device level, Section 4 discusses the process sensitivity at the circuit level. Section 5 concludes with a summary of results.

\section{SIMULATION METHODOLOGY}

A set of nominal NMOS and PMOS devices of physical gate length of $65 \mathrm{~nm}$ are designed and optimized for two different leakage currents $\left(\mathrm{I}_{\text {off }}\right)$ of $10 \mathrm{nA}$ and $100 \mathrm{nA}$, using disposable spacer technique[17]. A set of devices with a gate-to-source/drain overlap lengths $\left(\mathrm{L}_{\mathrm{ov}}\right)$ of $5 \mathrm{~nm}$, $0 \mathrm{~nm}$, and $-5 \mathrm{~nm}$ are generated by process simulations. The negative overlap suggests under lap from gate-tosource/drain extension. Figure 1 of NMOS illustrates gate-to-source/drain overlap length. To achieve the desired overlap length and leakage current, the overlap spacer thickness and the halo dose are appropriately varied. Devices with different overlap lengths are designed with leakage current constraint matched for the sub-nominal or best corner devices D-(defined in Table 1), for a fair comparison. It has been demonstrated that the gate length $\left(\mathrm{L}_{\mathrm{g}}\right)$ and gate oxide thickness $\left(\mathrm{T}_{\mathrm{ox}}\right)$ are the most significant parameters which impact the device variability at $65 \mathrm{~nm}$ [5], as at successive process generations $[1,18,19]$. To demonstrate the relevance of overlap length as a variability-aware device design parameter, a set of most significant process parameters of $\mathrm{L}_{\mathrm{g}^{\prime}} \mathrm{T}_{\mathrm{ox}}$, and the halo dose are considered, for process sensitivity study. It is assumed that gate length varies by $\pm 5 \mathrm{~nm}$, gate oxide thickness by $\pm 3 \mathrm{~A}^{\circ}$, and halo dose by $\pm 10 \%$, so as to produce best and worst corner devices, for the complete set of nominal NMOS/PMOS devices. To explore the performance at the nominal, best and worst process corners, the traditional worst case analysis is used, by selecting and combining extreme values for each of the parameters chosen that result in extreme values of device performance in terms of drive current $\mathrm{I}_{\text {on }}$.

All the devices are simulated, with drift-diffusion transport model, to obtain $\mathrm{I}_{\mathrm{d}}-\mathrm{V}_{\mathrm{gs}^{\prime}}$ and $\mathrm{C}_{\mathrm{gg}}-\mathrm{V}_{\mathrm{gs}}$ characteristics, and their respective drive current $I_{\text {on }}^{g s}$ and total device gate capacitance $\mathrm{C}_{\mathrm{gg}}$ are measured. For device simulations, physical effects such as doping dependence of mobility, field dependence of mobility, velocity saturation, channel carrier quantization, Band-to-Band-Tunneling (BTBT), and silicon band gap narrowing have been considered. Using these devices, a two-stage inverter gate, as shown in Figure 2, is simulated, to evaluate its transient behavior, using mixed-mode simulation approach. Both NMOS and PMOS are simulated at full device level. Transient analysis using mixed-mode simulations is used for the estimation of inverter delay, for its accuracy. An input pulse $V_{\text {in }}$ of 1 ps rise and fall times is applied and the stage delay of the first stage at its output $Y$ is monitored, when loaded by an identical second stage.

\section{PROCESS SENSITIVITY AT THE DEVICE LEVEL}

The drive current $\mathrm{I}_{\text {on }}$ and gate capacitance $\mathrm{C}_{\mathrm{gg}}$ of nominal and corner NMOS/PMOS devices are tabulated in

Table 1: Definition of device/circuit label

\begin{tabular}{llccc}
\hline Device/Circuit label & Device name & \multicolumn{3}{c}{ Deviation in } \\
\cline { 3 - 5 } & & $\mathrm{L}_{g}$ & $\mathrm{~T}_{\mathrm{ox}}$ & Halo dose \\
\hline $\mathrm{D}-/ \mathrm{C}-$ & Best corner & $-5 \mathrm{~nm}$ & $-3 \mathrm{~A}^{\circ}$ & $-10 \%$ \\
$\mathrm{D} 0 / \mathrm{C} 0$ & Nominal & $0 \mathrm{~nm}$ & $0 \mathrm{~A}^{\circ}$ & $0 \%$ \\
$\mathrm{D}+/ \mathrm{C}+$ & Worst corner & $+5 \mathrm{~nm}$ & $+3 \mathrm{~A}^{\circ}$ & $+10 \%$ \\
\hline
\end{tabular}

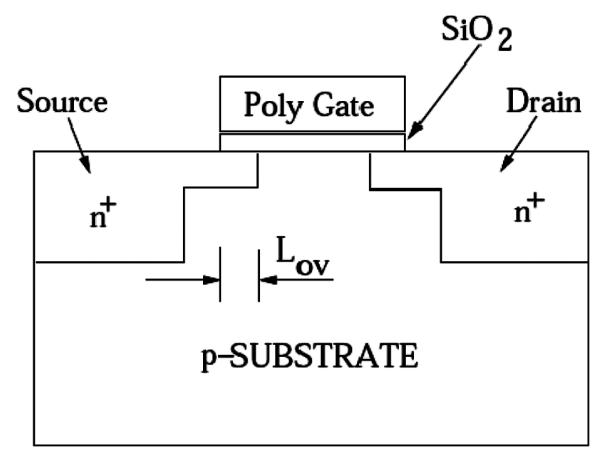

Figure 1: Schematic diagram of NMOS to illustrate gate-tosource/drain overlap length $\left(\mathrm{L}_{\mathrm{ov}}\right)$. 
[Downloaded free from http://www.jr.ietejournals.org on Tuesday, September 11, 2012, IP: 14.139.128.14] || Click here to download free Android application for this journal

Harish BP and Bhat N: Performance and Variability Trade-off with Gate-to-source/Drain Overlap Length

Tables 2 and 3, at $10 \mathrm{nA}$ and $100 \mathrm{nA}$ leakage, respectively. The percentage variation in $\mathrm{I}_{\text {on }}$ and $\mathrm{C}_{\mathrm{gg}}$ of best and worst corner devices, with respect to the nominal, at $10 \mathrm{nA}$ and $100 \mathrm{nA}$ leakage, are shown in

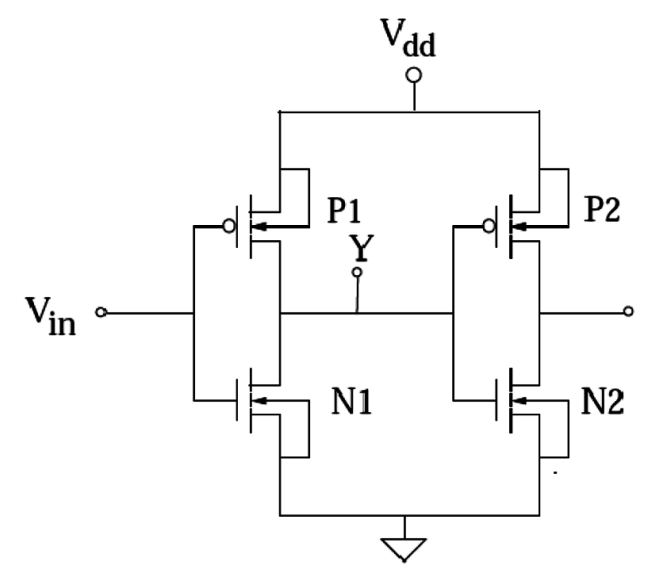

Figure 2: Two-stage CMOS inverter gate.

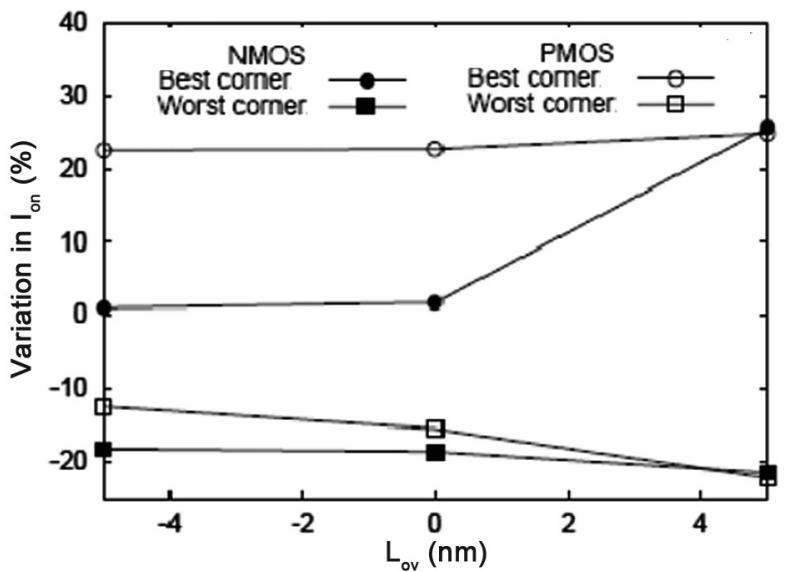

(a)
Figures 3 and 4 and the respective data are presented in Tables 4 and 5. It is observed that as $\mathrm{L}_{\text {ov }}$ reduces, percentage variation in $\mathrm{I}_{\text {on }}$ reduces for both NMOS and PMOS at both leakages. This may be attributed to increased area in the channel region and decreased impact of random dopant fluctuations. Hence, smaller $\mathrm{L}_{\mathrm{ov}}$ produces better variability performance. As $\mathrm{L}_{\mathrm{ov}}$ is reduced from 5 to $0 \mathrm{~nm}$, the variation in $\mathrm{I}_{\mathrm{on}}$ reduces from $25.7 \%$ to $1.7 \%$ for best corner device in NMOS and from $22.3 \%$ to $15.5 \%$ for worst corner device in PMOS, at a leakage of $10 \mathrm{nA}$. However, at $100 \mathrm{nA}$ leakage, the respective values are from $21.1 \%$ to $1.1 \%$ in NMOS and from $18.7 \%$ to $14.8 \%$ in PMOS. However, as $\mathrm{L}_{\text {ov }}$ is reduced from 0 to $-5 \mathrm{~nm}$, the reduction in variability of $\mathrm{I}_{\mathrm{on}}$ is negligible for NMOS/PMOS, at both leakages. Also, the reduction in variability for worst corner NMOS and best corner PMOS is small. The process for NMOS can be biased toward the best corner and for PMOS toward the worst corner for an improved variability performance, but at the cost of process complexity.

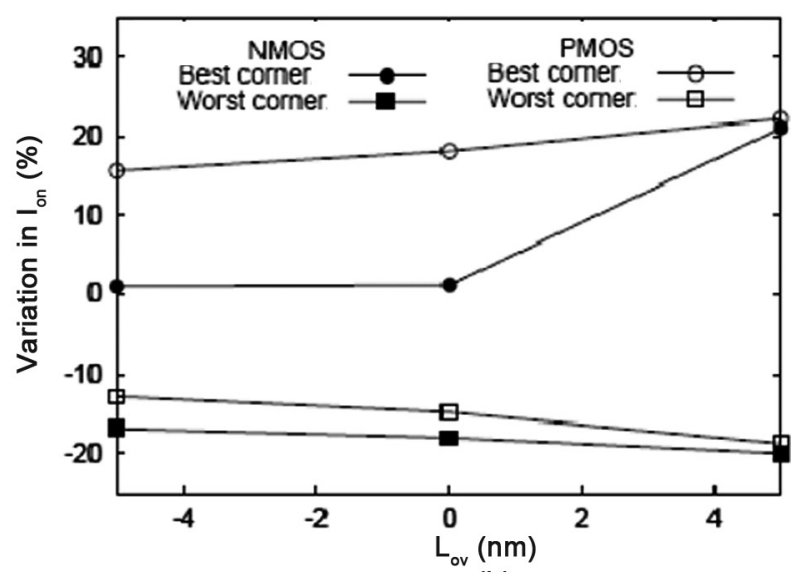

(b)

Figure 3: Percentage variation in $I_{\text {on }}$ of NMOS/PMOS devices: (a) $I_{\text {off }}=10 n A(b) I_{\text {off }}=100 \mathrm{nA}$.

Table 2: The drive current Ion in $\mu \mathrm{A}$ and gate capacitance $\mathrm{C}_{\mathrm{gg}}$ in $\mathrm{fF}$, of NMOS/PMOS for a leakage of $\mathrm{I}_{\mathrm{off}}=10 \mathrm{nA}$, with $\mathrm{L}_{\mathrm{ov}}$ as a design parameter

\begin{tabular}{|c|c|c|c|c|c|c|c|c|c|c|c|c|}
\hline \multirow{3}{*}{$\frac{\mathrm{L}_{\text {ov }}}{\text { Device }}$} & \multicolumn{6}{|c|}{ NMOS } & \multicolumn{6}{|c|}{ PMOS } \\
\hline & \multicolumn{2}{|c|}{$5 \mathrm{~nm}$} & \multicolumn{2}{|c|}{$0 \mathrm{~nm}$} & \multicolumn{2}{|c|}{$-5 \mathrm{~nm}$} & \multicolumn{2}{|c|}{$5 \mathrm{~nm}$} & \multicolumn{2}{|c|}{$0 \mathrm{~nm}$} & \multicolumn{2}{|c|}{$-5 n m$} \\
\hline & $\mathrm{I}_{\text {on }}$ & $\mathrm{C}_{g g}$ & $\mathrm{I}_{\text {on }}$ & $\mathrm{C}_{g g}$ & $\mathrm{I}_{\text {on }}$ & $\mathrm{C}_{g g}$ & $I_{\text {on }}$ & $\mathrm{C}_{g g}$ & $\mathrm{I}_{\text {on }}$ & $\mathrm{C}_{g g}$ & $\mathrm{I}_{\text {on }}$ & $\mathrm{C}_{g g}$ \\
\hline Best & 809.99 & 1.321 & 579.51 & 1.318 & 370.59 & 1.316 & 392.66 & 1.293 & 309.51 & 1.298 & 187.17 & 1.296 \\
\hline Nominal & 644.55 & 1.304 & 569.73 & 1.311 & 366.81 & 1.309 & 314.29 & 1.219 & 252.15 & 1.221 & 152.55 & 1.218 \\
\hline Worst & 505.06 & 1.238 & 463.44 & 1.241 & 299.74 & 1.239 & 244.14 & 1.127 & 212.9 & 1.130 & 133.49 & 1.129 \\
\hline
\end{tabular}

Table 3: The drive current Ion in $\mu \mathrm{A}$ and gate capacitance $\mathrm{C}_{\mathrm{gg}}$ in $\mathrm{fF}$, of NMOS/PMOS for a leakage of $\mathrm{I}_{\text {off }}=100 \mathrm{nA}$, with $\mathrm{L}_{\text {ov }}$ as a design parameter

\begin{tabular}{|c|c|c|c|c|c|c|c|c|c|c|c|c|}
\hline \multirow{3}{*}{$\frac{L_{\text {ov }}}{\text { Device }}$} & \multicolumn{6}{|c|}{ NMOS } & \multicolumn{6}{|c|}{ PMOS } \\
\hline & \multicolumn{2}{|c|}{$5 \mathrm{~nm}$} & \multicolumn{2}{|c|}{$0 \mathrm{~nm}$} & \multicolumn{2}{|c|}{$-5 n m$} & \multicolumn{2}{|c|}{$5 \mathrm{~nm}$} & \multicolumn{2}{|c|}{$0 \mathrm{~nm}$} & \multicolumn{2}{|c|}{$-5 n m$} \\
\hline & $\mathrm{I}_{\text {on }}$ & $\mathrm{C}_{\mathrm{gg}}$ & $\mathrm{I}_{\text {on }}$ & $\mathrm{C}_{\mathrm{gg}}$ & $\mathrm{I}_{\text {on }}$ & $\mathrm{C}_{\mathrm{gg}}$ & $\mathrm{I}_{\text {on }}$ & $C_{g g}$ & $\mathrm{I}_{\text {on }}$ & $C_{g g}$ & $\mathrm{I}_{\text {on }}$ & $\mathrm{C}_{g g}$ \\
\hline Best & 917.12 & 1.330 & 673.08 & 1.322 & 456.25 & 1.321 & 449.46 & 1.322 & 349.82 & 1.314 & 225.24 & 1.311 \\
\hline Nominal & 757.37 & 1.318 & 665.47 & 1.321 & 451.73 & 1.320 & 367.76 & 1.229 & 296.06 & 1.231 & 194.77 & 1.229 \\
\hline Worst & 605.71 & 1.248 & 545.59 & 1.243 & 375.54 & 1.240 & 298.84 & 1.148 & 252.15 & 1.145 & 169.81 & 1.144 \\
\hline
\end{tabular}


[Downloaded free from http://www.jr.ietejournals.org on Tuesday, September 11, 2012, IP: 14.139.128.14] || Click here to download free Android application for this journal

Harish BP and Bhat N: Performance and Variability Trade-off with Gate-to-source/Drain Overlap Length

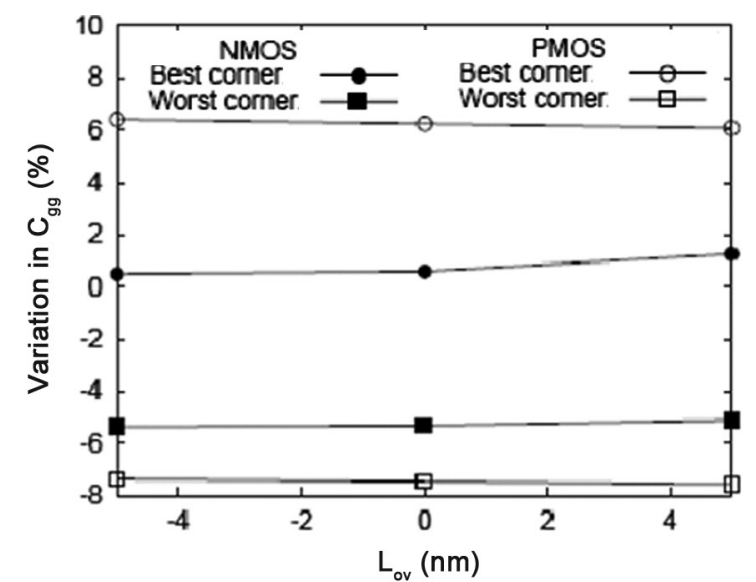

(a)

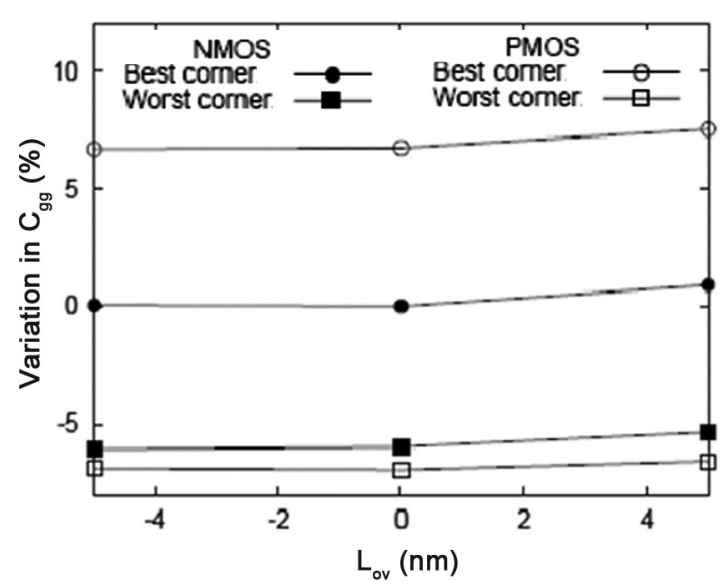

(b)

Figure 4: Percentage variation in $C_{\mathrm{gg}}$ of NMOS/PMOS devices: (a) $\mathrm{I}_{\text {off }}=10 \mathrm{nA}$ (b) $\mathrm{I}_{\text {off }}=100 \mathrm{nA}$.

Table 4: Variation in $\mathrm{I}_{\text {on }}$ and $\mathrm{C}_{\mathrm{gg}}$ of NMOS/PMOS devices for a leakage of $\mathrm{I}_{\text {off }}=10 \mathrm{nA}$, with $\mathrm{L}_{\text {ov }}$ as a design parameter

\begin{tabular}{|c|c|c|c|c|c|c|c|c|c|c|c|c|}
\hline \multirow{3}{*}{$\frac{\mathrm{L}_{\text {ov }}}{\text { Device }}$} & \multicolumn{6}{|c|}{ NMOS } & \multicolumn{6}{|c|}{ PMOS } \\
\hline & \multicolumn{2}{|c|}{$5 \mathrm{~nm}$} & \multicolumn{2}{|c|}{$0 \mathrm{~nm}$} & \multicolumn{2}{|c|}{$-5 n m$} & \multicolumn{2}{|c|}{$5 \mathrm{~nm}$} & \multicolumn{2}{|c|}{$0 \mathrm{~nm}$} & \multicolumn{2}{|c|}{$-5 n m$} \\
\hline & $\mathrm{I}_{\text {on }}$ & $\mathrm{C}_{g g}$ & $\mathrm{I}_{\text {on }}$ & $\mathrm{C}_{g g}$ & $\mathrm{I}_{\text {on }}$ & $\mathrm{C}_{g g}$ & $\mathrm{I}_{\text {on }}$ & $\mathrm{C}_{g g}$ & $I_{\text {on }}$ & $\mathrm{C}_{g \mathrm{~g}}$ & $\mathrm{I}_{\text {on }}$ & $\mathrm{C}_{g g}$ \\
\hline Best & +25.67 & +1.26 & +1.72 & +0.55 & +1.03 & +0.50 & +24.94 & +6.06 & +22.75 & +6.23 & +22.60 & +6.40 \\
\hline Worst & -21.64 & -5.10 & -18.66 & -5.30 & -18.28 & -5.35 & -22.32 & -7.55 & -15.55 & -7.45 & -12.50 & -7.36 \\
\hline
\end{tabular}

Table 5: Variation in $\mathrm{I}_{\text {on }}$ and $\mathrm{C}_{\mathrm{gg}}$ of NMOS/PMOS devices for a leakage of $\mathrm{I}_{\text {off }}=100 \mathrm{nA}$, with $\mathrm{L}_{\mathrm{ov}}$ as a design parameter

\begin{tabular}{|c|c|c|c|c|c|c|c|c|c|c|c|c|}
\hline \multirow{3}{*}{$\frac{\mathrm{L}_{\text {ov }}}{\text { Device }}$} & \multicolumn{4}{|c|}{ NMOS } & \multicolumn{2}{|l|}{+} & \multicolumn{6}{|c|}{ PMOS } \\
\hline & \multicolumn{2}{|c|}{$5 \mathrm{~nm}$} & \multicolumn{2}{|c|}{$0 \mathrm{~nm}$} & \multicolumn{2}{|c|}{$-5 \mathrm{~nm}$} & \multicolumn{2}{|c|}{$5 \mathrm{~nm}$} & \multicolumn{2}{|c|}{$0 \mathrm{~nm}$} & \multicolumn{2}{|c|}{$-5 n m$} \\
\hline & $I_{\text {on }}$ & $\mathrm{C}_{g g}$ & $I_{\text {on }}$ & $\mathrm{C}_{\mathrm{gg}}$ & $\mathrm{I}_{\text {on }}$ & $\mathrm{C}_{g g}$ & $\mathrm{I}_{\text {on }}$ & $\mathrm{C}_{g g}$ & $I_{\text {on }}$ & $\mathrm{C}_{g g}$ & $I_{\text {on }}$ & $\mathrm{C}_{g 9}$ \\
\hline Best & +21.09 & +0.93 & +1.14 & +0.02 & +1.0 & +0.07 & +22.21 & +7.54 & +18.16 & +6.75 & +15.64 & +6.70 \\
\hline Worst & -20.02 & -5.32 & -18.01 & -5.96 & -16.86 & -6.06 & -18.74 & -6.57 & -14.83 & -6.96 & -12.81 & -6.89 \\
\hline
\end{tabular}

It can also be seen that as $\mathrm{L}_{\text {ov }}$ reduces, the device drive current $\mathrm{I}_{\text {on }}$ reduces degrading the device performance of both NMOS/PMOS and at both leakages. As $\mathrm{L}_{\text {ov }}$ is reduced from $5 \mathrm{~nm}$ to $0 \mathrm{~nm}, \mathrm{I}_{\text {on }}$ reduces by about $10 \%$ for NMOS and $20 \%$ for PMOS and as $\mathrm{L}_{\text {ov }}$ is reduced from 5 to $-5 \mathrm{~nm}$, $\mathrm{I}_{\text {on }}$ reduces by about $40 \%$ for NMOS and $50 \%$ for PMOS, at both leakages and for nominal devices. With variation in $\mathrm{L}_{\mathrm{ov}}$, the total gate capacitance $\mathrm{C}_{\mathrm{gg}}$ is more or less constant for NMOS/PMOS at both leakages, as seen in Tables 2 and 3 . As $\mathrm{L}_{\text {ov }}$ is reduced from 5 to $0 \mathrm{~nm}$, the percentage variability in $\mathrm{I}_{\text {on }}$ reduces from $25.7 \%$ to $1.7 \%$ in NMOS and from $22.3 \%$ to $15.5 \%$ in PMOS and as $\mathrm{L}_{\mathrm{ov}}$ is reduced from 5 to $-5 \mathrm{~nm}$, from $25.7 \%$ to $1.0 \%$ in NMOS and from $22.3 \%$ to $12.5 \%$ in PMOS. Similar trend in variation in percentage variability in $\mathrm{I}_{\text {on }}$ can be seen at $100 \mathrm{nA}$ leakage as well. Thus, it is demonstrated that overlap should be made as large as possible for better drive current performance and as small as possible for better drive current variability. Hence, there exists a trade-off between performance and variability at the device level with $\mathrm{L}_{\mathrm{ov}}$ as the design parameter. The design trade-off between the drive current $\mathrm{I}_{\text {on }}$ and its variability is illustrated in Figures 5 and 6, for 10 nA and 100 nA leakage, respectively. Although the percentage variation in $\mathrm{I}_{\text {on }}$ is expressed with respect to the $\mathrm{I}_{\text {on }}$ at $+5 \mathrm{~nm}$ overlap, the percentage $I_{\text {on }}$ variability at a process corner for a given overlap is expressed with respect to the respective nominal device.

Considering that the reduction in variability is insignificant and reduction in $\mathrm{I}_{\text {on }}$ is significant, when $\mathrm{L}_{\text {ov }}$ is reduced from 0 to $-5 \mathrm{~nm}$ at both leakages and for both $\mathrm{NMOS} / \mathrm{PMOS}$, an $\mathrm{L}_{\text {ov }}=0 \mathrm{~nm}$ may be recommended for an optimal combination of performance and variability, at the device level. Thus, by reducing $\mathrm{L}_{\mathrm{ov}}$ from 5 to $0 \mathrm{~nm}$, a significant reduction in variability to the extent of $(1-(579.51-463.44) /(809.99-505.06))=62 \%$ in NMOS and $(1-(309.51-212.9) /(392.66-244.14))=35 \%$ in PMOS can be achieved at the cost of degradation in $\mathrm{I}_{\text {on }}$ to the extent of $10 \%$ in NMOS and $20 \%$ in PMOS. The reduction in variability in drive current is expressed in terms of worst to best corner spread in drive current.

\section{PROCESS SENSITIVITY AT THE CIRCUIT LEVEL}

The nominal values of falling edge and rising edge delays of inverter circuit with $10 \mathrm{nA}$ and $100 \mathrm{nA}$ 
[Downloaded free from http://www.jr.ietejournals.org on Tuesday, September 11, 2012, IP: 14.139.128.14] || Click here to download free Android application for this journal

Harish BP and Bhat N: Performance and Variability Trade-off with Gate-to-source/Drain Overlap Length

leakage devices are tabulated in Tables 6 and 7. The percentage variation in falling edge and rising edge delays of inverter circuit of best and worst corner devices, with respect to the nominal, at leakage values of $10 \mathrm{nA}$ and $100 \mathrm{nA}$, is shown in Figure 7 and the respective data are presented in Tables 8 and 9, respectively.

The variation in falling edge delay reduces from $11.9 \%$ to $6 \%$ for best corner device and the variation in rising

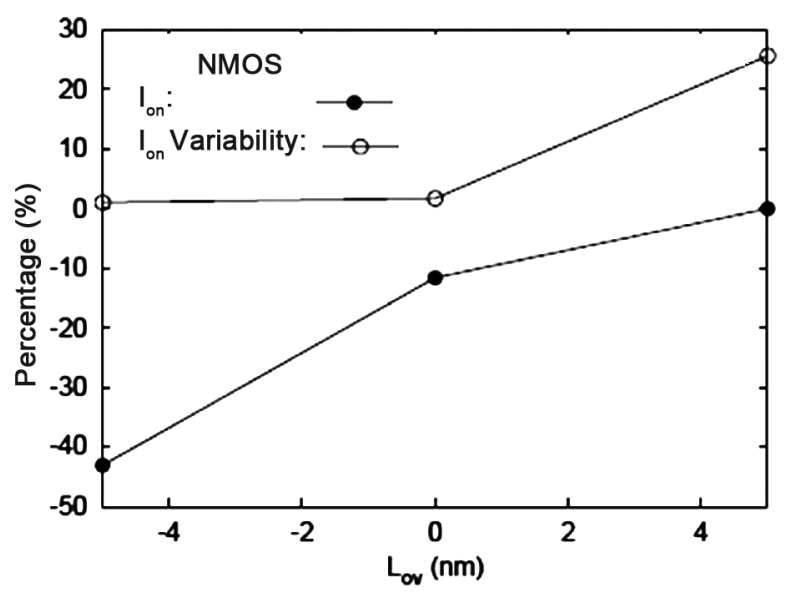

(a)

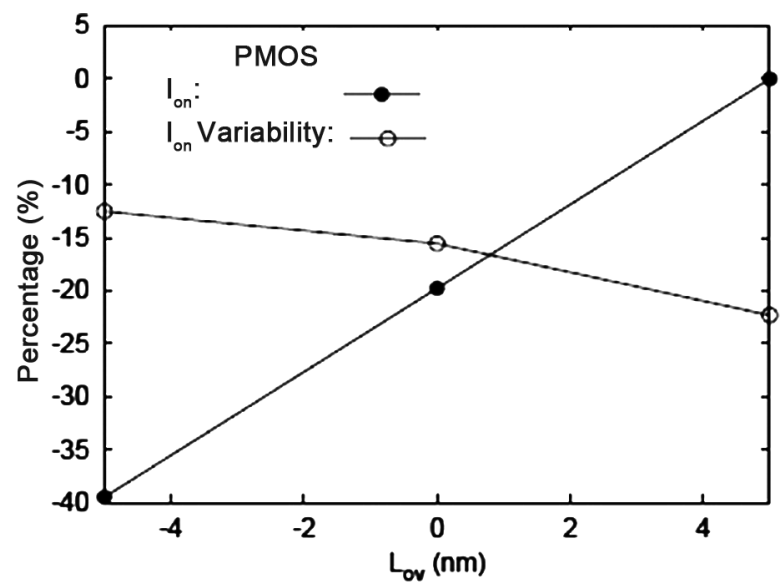

(b)

Figure 5: Trade-off between percentage variation in $I_{\text {on }}$ and its variability for leakage of $10 \mathrm{nA}$ : (a) NMOS (b) PMOS.

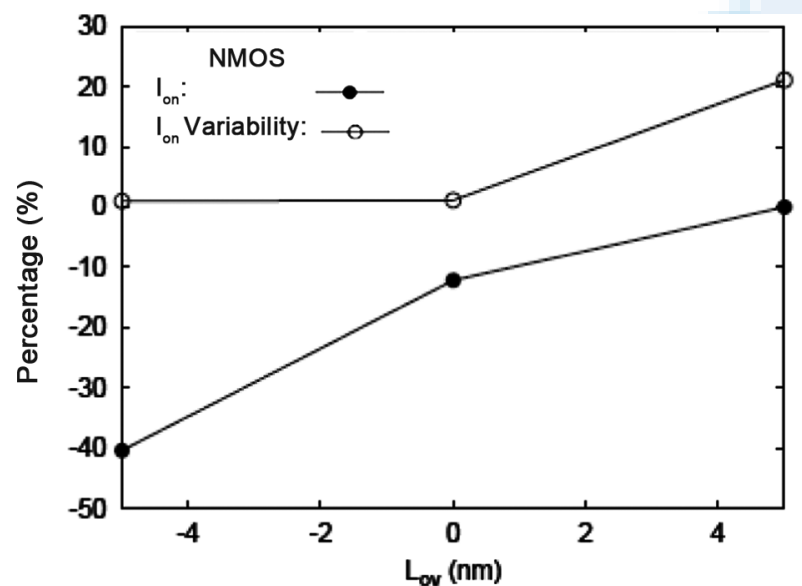

(a)

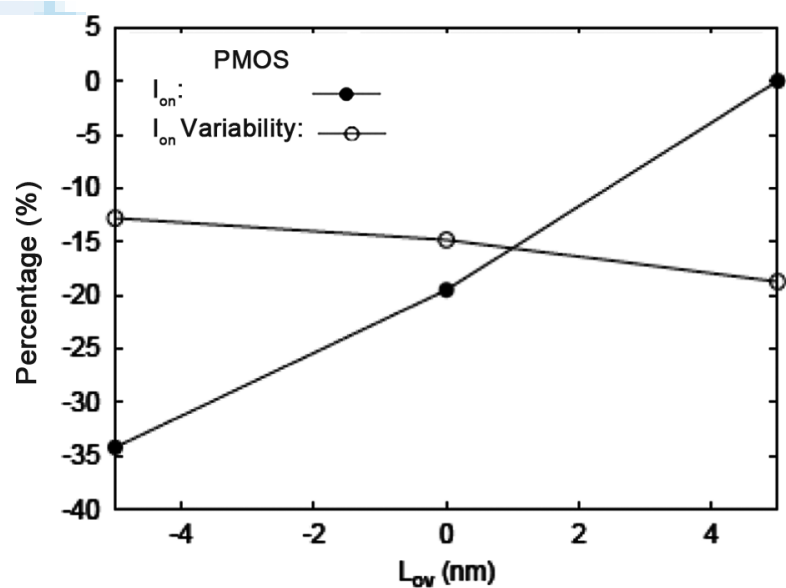

(b)

Figure 6: Trade-off between percentage variation in $\mathrm{I}_{\text {on }}$ and its variability for leakage of $100 \mathrm{nA}$ : (a) NMOS (b) PMOS.

Table 6: The falling edge and rising edge delays of inverter with $10 \mathrm{nA}$ leakage devices (in ps)

\begin{tabular}{lcccccc}
\hline & \multicolumn{3}{c}{ Falling edge delay } & \multicolumn{3}{c}{ Rising edge delay } \\
\cline { 2 - 7 } $\mathrm{L}_{\text {ov }}$ & $5 \mathrm{~nm}$ & $0 \mathrm{~nm}$ & $-5 \mathrm{~nm}$ & $5 \mathrm{~nm}$ & $0 \mathrm{~nm}$ & $-5 \mathrm{~nm}$ \\
\hline Best & 4.64 & 5.99 & 8.47 & 5.67 & 7.23 & 12.23 \\
Nominal & 5.27 & 5.65 & 7.90 & 6.99 & 8.77 & 14.81 \\
Worst & 6.19 & 6.59 & 8.96 & 8.41 & 9.99 & 15.62 \\
\hline
\end{tabular}

Table 8: Variation in falling edge and rising edge delays of inverter with $10 \mathrm{nA}$ leakage devices (in \%)

\begin{tabular}{lccccccc}
\hline & \multicolumn{3}{c}{ Falling edge delay } & & \multicolumn{3}{c}{ Rising edge delay } \\
\cline { 2 - 4 } \cline { 7 - 8 } $\mathrm{L}_{\text {ov }}$ & $5 \mathrm{~nm}$ & $0 \mathrm{~nm}$ & $-5 \mathrm{~nm}$ & & $5 \mathrm{~nm}$ & $0 \mathrm{~nm}$ & $-5 \mathrm{~nm}$ \\
\hline Best corner & -11.87 & +6.05 & +7.30 & & -18.88 & -17.58 & -17.42 \\
Worst corner & +17.45 & +16.62 & +13.39 & & +20.33 & +13.87 & +5.46 \\
\hline
\end{tabular}

Table 7: The falling edge and rising edge delays of inverter circuit $100 \mathrm{nA}$ leakage devices (in ps)

\begin{tabular}{lcccccccc}
\hline & \multicolumn{3}{c}{ Falling edge delay } & & \multicolumn{3}{c}{ Rising edge delay } \\
\cline { 2 - 4 } $\mathrm{L}_{\text {ov }}$ & $5 \mathrm{~nm}$ & $0 \mathrm{~nm}$ & $-5 \mathrm{~nm}$ & & $5 \mathrm{~nm}$ & $0 \mathrm{~nm}$ & $-5 \mathrm{~nm}$ \\
\hline Best & 4.36 & 5.53 & 7.61 & & 5.21 & 6.66 & 10.32 \\
Nominal & 4.84 & 5.26 & 7.19 & & 6.22 & 7.78 & 12.00 \\
Worst & 5.67 & 6.05 & 8.11 & & 7.18 & 8.55 & 12.80 \\
\hline
\end{tabular}

Table 9: Variation in falling edge and rising edge delays of inverter with $100 \mathrm{nA}$ leakage devices (in \%)

\begin{tabular}{lccccccc}
\hline & \multicolumn{3}{c}{ Falling edge delay } & & \multicolumn{3}{c}{ Rising edge delay } \\
\cline { 2 - 4 } $\mathrm{L}_{\text {ov }}$ & $5 \mathrm{~nm}$ & $0 \mathrm{~nm}$ & $-5 \mathrm{~nm}$ & & $5 \mathrm{~nm}$ & $0 \mathrm{~nm}$ & $-5 \mathrm{~nm}$ \\
\hline Best corner & -9.88 & +5.30 & +5.76 & & -16.25 & -14.45 & -13.99 \\
Worst corner & +17.21 & +15.15 & +12.79 & & +15.46 & +9.87 & +6.68 \\
\hline
\end{tabular}


[Downloaded free from http://www.jr.ietejournals.org on Tuesday, September 11, 2012, IP: 14.139.128.14] || Click here to download free Android application for this journal

Harish BP and Bhat N: Performance and Variability Trade-off with Gate-to-source/Drain Overlap Length

edge delay reduces from $20.3 \%$ to $13.8 \%$ for worst corner device, as $\mathrm{L}_{\mathrm{ov}}$ is reduced from 5 to $0 \mathrm{~nm}$, at 10 nA leakage. However, at $100 \mathrm{nA}$ leakage, the respective values are from $9.9 \%$ to $5.3 \%$ for falling edge delay and from $15.5 \%$ to $9.8 \%$ for rising edge delay. Similarly, as $\mathrm{L}_{\mathrm{ov}}$ is reduced from 0 to $-5 \mathrm{~nm}$, the variation in falling edge delay increases from $6.1 \%$ to $7.3 \%$ for best corner device and the variation in rising edge delay reduces from $13.8 \%$ to $5.4 \%$ for worst corner device, at a leakage of $10 \mathrm{nA}$. The respective values, for $100 \mathrm{nA}$ leakage, are from $5.3 \%$ to $5.7 \%$ and $9.9 \%$ to $6.6 \%$. For all cases of rising and falling edge delays at various overlap lengths, at both leakages and for best corner and worst corner devices, $\mathrm{I}_{\text {on }}$ variations dominate over $C_{g g}$ variations, except for falling edge delay at $\mathrm{L}_{\mathrm{ov}}=0 \mathrm{~nm}$ and $-5 \mathrm{~nm}$ at both leakages where $\mathrm{C}_{\mathrm{gg}}$ variations dominate over $\mathrm{I}_{\text {on }}$ variations. This explains the rise in delay and its variability seen for this case.

It can be observed that as $\mathrm{L}_{\text {ov }}$ is reduced from 5 to $0 \mathrm{~nm}$, falling edge delay increases by about $7 \%$ and rising edge delay increases by about $25 \%$ and as $\mathrm{L}_{\text {ov }}$ is reduced from
5 to $-5 \mathrm{~nm}$, falling edge delay increases by about $50 \%$ and rising edge delay increases by about $100 \%$, at both leakages and for inverter circuit with nominal devices. As $\mathrm{L}_{\mathrm{ov}}$ is reduced from 5 to $0 \mathrm{~nm}$, the percentage delay variability reduces from $17.5 \%$ to $16.6 \%$ for falling edge and from $20.3 \%$ to $14 \%$ for rising edge and as $\mathrm{L}_{\mathrm{ov}}$ is reduced from 5 to $-5 \mathrm{~nm}$, from $17.5 \%$ to $13.4 \%$ for falling edge and from $20.3 \%$ to $5.5 \%$ for rising edge. Similar trend in variation in percentage variability in delay can be seen at $100 \mathrm{nA}$ leakage as well. Hence, the reduction in variability in delay trades with delay performance. The design trade-off between delay performance and delay variability is illustrated in Figures 8 and 9, for $10 \mathrm{nA}$ and $100 \mathrm{nA}$ leakage, respectively. Although the percentage delay is expressed with respect to the delay at $+5 \mathrm{~nm}$ overlap, the percentage delay variability at a process corner for a given overlap is expressed with respect to the respective nominal device. Thus, it is demonstrated that for better delay performance, overlap should be made as large as possible, and for better delay variability, overlap should be made as

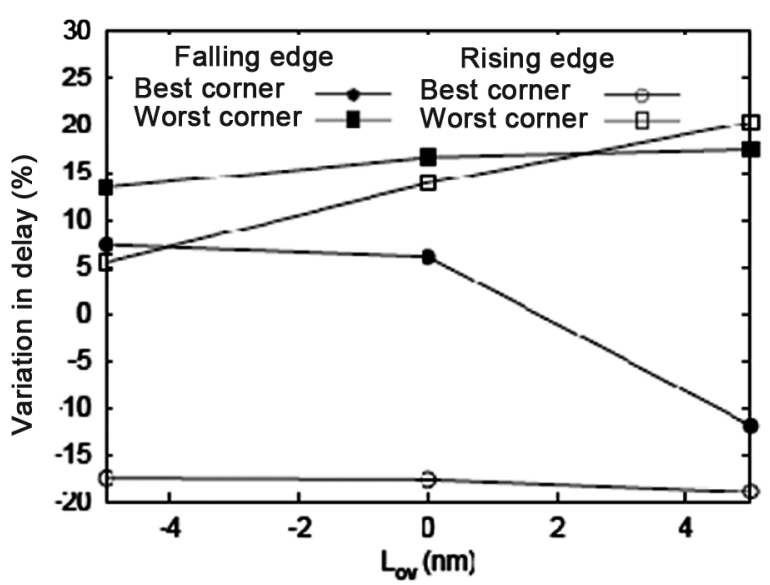

(a)

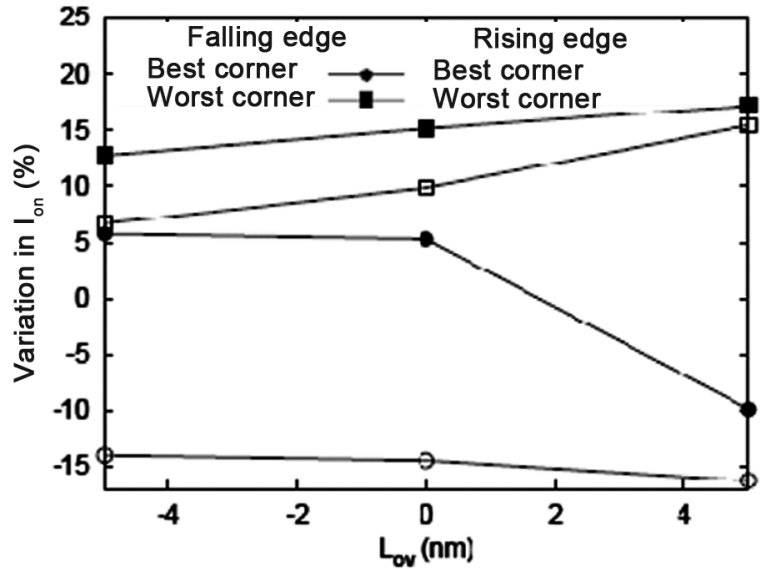

(b)

Figure 7: Percentage variation in falling and rising edge delays of inverter gate: (a) $I_{\text {off }}=10 \mathrm{nA}$ (b) $\mathrm{I}_{\text {off }}=100 \mathrm{nA}$.

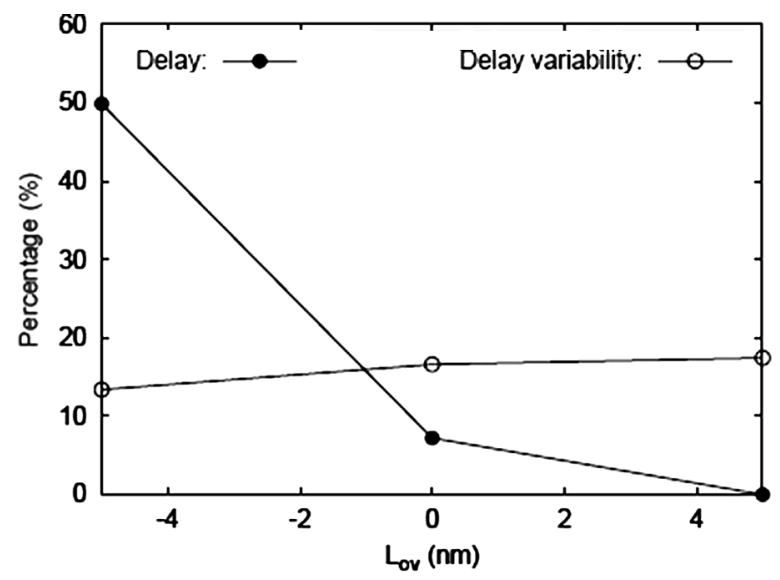

(a)

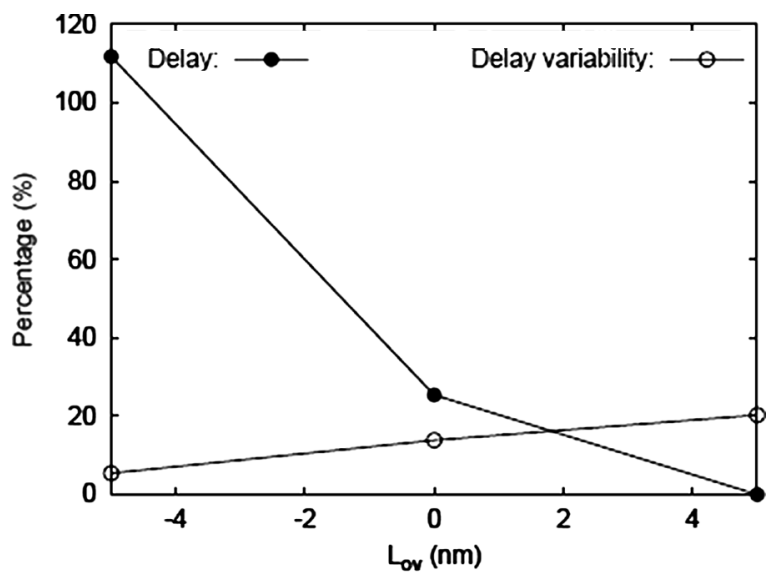

(b)

Figure 8: Trade-off between percentage variation in delay and delay variability of inverter gate for leakage of $10 \mathrm{nA}$ : (a) Falling edge (b) Rising edge. 
[Downloaded free from http://www.jr.ietejournals.org on Tuesday, September 11, 2012, IP: 14.139.128.14] || Click here to download free Android application for this journal

Harish BP and Bhat N: Performance and Variability Trade-off with Gate-to-source/Drain Overlap Length

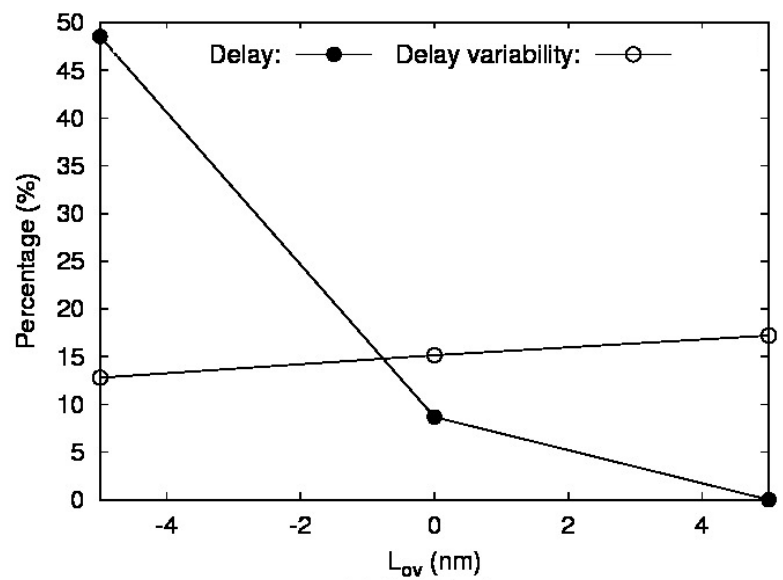

(a)

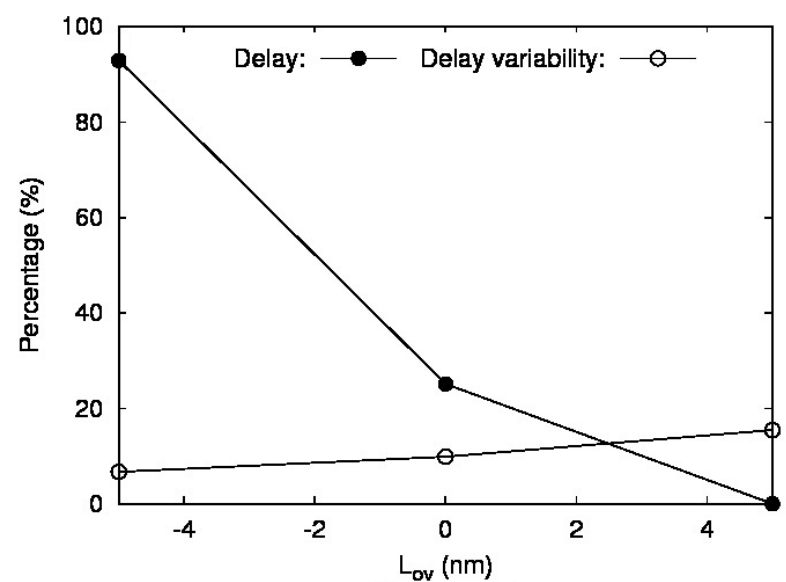

(b)

Figure 9: Trade-off between percentage variation in delay and delay variability of inverter gate for leakage of $100 \mathrm{nA}$ : (a) Falling edge (b) Rising edge.

small as possible.

As $\mathrm{L}_{\text {ov }}$ is reduced from 5 to $0 \mathrm{~nm}$, the reduction in variability in delay is $(1-(6.59-5.99) /(6.19-4.64))=61 \%$ and as $\mathrm{L}_{\text {ov }}$ is reduced from 5 to $-5 \mathrm{~nm}$, the reduction in variability in delay is $(1-(8.96-8.47) /(6.19-4.64))=68 \%$. The reduction invariability in delay is expressed in terms of worst to best corner delay spread. Hence, it is clear that as $\mathrm{L}_{\text {ov }}$ is reduced from 5 to $0 \mathrm{~nm}$, the reduction in variability in delay is significant; the corresponding increase in delay is limited. Also, as $\mathrm{L}_{\text {ov }}$ is reduced from 0 to $-5 \mathrm{~nm}$, the increase in delay is significant; the reduction in variability in delay is negligible. Hence, for an optimal combination of delay performance and delay variability, an overlap of $0 \mathrm{~nm}$ is recommended at $65 \mathrm{~nm}$ gate length.

\section{CONCLUSIONS}

The impact of gate-to-source/drain overlap length on performance and variability, at two different leakage currents, is evaluated by taking variations in significant process parameters. The Worst-Case-Analysis (WCA) approach is used to study the inverter delay variations at the process corners. The drive current of the device for device robustness and stage delay of an inverter for circuit robustness are selected as performance metrics. Although a smaller overlap length leads to better variability at the cost of performance, a larger overlap length results in better performance at the cost of increased variability. The design trade-off between performance and variability is demonstrated both at the device level and circuit level. An optimal value of overlap length of $0 \mathrm{~nm}$ is recommended at $65 \mathrm{~nm}$ gate length for a reasonable combination of performance and variability. The device design can be optimized for performance and variability with respect to overlap length for any CMOS process node.

\section{ACKNOWLEDGMENT}

Authors would like to acknowledge the Department of Science and Technology, Government of India, for supporting this project.

\section{REFERENCES}

1. Semiconductor Industry Association, The International Technology Roadmap for Semiconductors (ITRS) 2009 Edition, Available from: http://www.itrs.net/Links/2009ITRS/Home2009.htm [Last cited on 2011 Apr 08].

2. C Michael, and M Ismail, "Statistical modeling for computer-aided design of MOS VLSI circuits", Kluwer Academic Publishers; 2001.

3. H P Tuinhout, "Impact of parametric mismatch and fluctuations on performance and yield of deep-submicron CMOS technologies", Proc. of European Solid State Device Research Conference, pp. 95101, 2002.

4. J A G Jess, K Kalafala, S R. Naidu, R H J M Otten and C Visweswariah, "Statistical timing for parametric yield prediction of digital integrated circuits", IEEE Trans. Computer-Aided Design of ICs and Systems, Vol. 25, No. 11, pp. 2376-92, Nov. 2006

5. B P Harish, N Bhat, and M B Patil, "Analytical modeling of CMOS circuit delay distribution due to concurrent variations in multiptle processes", Solid-State Electronics, Vol. 50, No.7-8, pp. 1252-60, JulyAugust 2006.

6. B P Harish, N Bhat, and M B Patil, "On a generalized framework for modeling the effects of process variations on circuit delay performance using response surface methodology", IEEE Trans. on Computer-Aided Design of ICs and Systems, Vol. 26, No.3,pp.60614,Mar.2007.

7. S Zhang, $\vee$ Wason, and K Banerjee, "A probabilistic framework to estimate full-chip subthreshold leakage power distribution considering within-die and die-to-die P-T-V variations", Proc. of Int. Symposium on Low Power Electronics and Design, pp. 156-61, 2004.

8. H Chang, and S S Sapatnekar, "Full-chip analysis of leakage power under process variations, including spatial correlations", Proc. of Design Automation Conference, pp.523-8, 2005.

9. B P Harish, N Bhat, and M B Patil, "Hybrid-CV Modeling for Estimating the Variability in Dynamic Power", Journal of Low Power Electronics, Vol. 4, No. 3, pp.263-74, Dec. 2008.

10. T Y Chan, A T Wu, P K Ko, and Chenming Hu, "Effects of the gateto-drain/source overlap on MOSFET characteristics", IEEE Electron Device Letters, Vol. EDL-8, No.7, pp. 326-8, July. 1987.

11. M Y Kwong, R Kasnavi, P Griffn, J D Plummer, and R W Dutton, “Impact 
[Downloaded free from http://www.jr.ietejournals.org on Tuesday, September 11, 2012, IP: 14.139.128.14] || Click here to download free Android application for this journal

Harish BP and Bhat N: Performance and Variability Trade-off with Gate-to-source/Drain Overlap Length

of lateral source/drain abruptness on device performance", IEEE Trans. on Electron Devices, Vol.49, No.11, pp.1882-90, Nov. 2002.

12. S Thompson, P Packan, T Ghani, M Stettler, M Alavi, and I Post, et al., "Source/Drain extension scaling for $0.1 \mu \mathrm{m}$ and below channel length MOSFETs", Proc. of IEEE Int. Symposiumon VLSI Technology, pp.132-3, 1998.

13. K Maitra, and N Bhat, "Impact of gate-to-source/drain overlap length on 80-nm CMOS circuit performance", IEEE Trans. On Electron Devices, Vol.51, No. 3, pp. 409-14, Mar. 2004.

14. Hyunjin Lee, Sung-il Chang, Jongho Lee, and Hyungcheol Shin, "Characteristics of MOSFET with non-overlapped source-drain to gate region", Proc. of Int. Conf. on Microelectronics, Vol. 2, pp.439-41, May. 2002.

15. V Palankovski, N Belova, T Grasser, H Puchner, S Aronowitz, and S Selberherr, "A methodology for deep sub-0.25 $\mu \mathrm{m}$ CMOS technology prediction", IEEE Trans. on Electron Devices, Vol.48,
No.10, pp. 2331-6, Oct. 2001.

16. Sentaurus TCAD, Synopsys, available from: http://www.synopsys. com/Tools/TCAD/Pages/default.aspx [Last cited on 2011 Apr. 08].

17. J R Pfiester, L C Parrillo, M Woo, H Kawasaki, B Boeck, and E Travis, et al., "An integrated $0.5 \mu \mathrm{m}$ CMOS disposable TiN LDD/ salicide spacer technology", Proc. of IEDM Tech. Digest, pp.781-4, Dec.1989.

18. R Sitte, S Dimitrijev, and H B Harrison, "Device parameter changes caused by manufacturing fluctuations of deep submicron MOSFETs", IEEE Trans. on Electron Devices, Vol. 41, No.11, pp. 2210-5, Nov. 1994.

19. P M Zeitzoff, A F Tasch, W E Moore, S A Khan, and D Angelo, "Modeling of manufacturing sensitivity and of statistically based process control requirements for a $0.18 \mu \mathrm{m}$ NMOS device", Proc. of Int. Conf. on Characterization and Metrology for ULSI Technology, pp.73-81, Nov. 1998.

\section{AUTHORS}

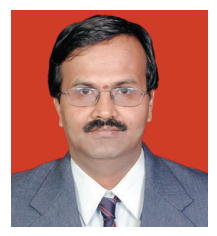

B. P. Harish received Ph.D. in Electrical Communication Engineering from Indian Institute of Science in the year 2007, M.Tech. degree from Karnataka Regional Engineering College (Presently NIT), Surathkal, Karnataka, in 1993, B. E. degree in Electronics and Communication Engineering, in 1990. In 1995, he joined the Dept. of Electrical Engineering, University Visvesvaraya College of Engineering, Bangalore University, Bangalore as a faculty. He is presently working as Associate Professor in the Dept. of Electrical Engineering in the same Institute. His research interests include CMOS process technologies, variability studies and device modeling. He has contributed 12 technical papers in various journals and conferences.

He is conferred with the Seshagiri Kaikani Medal for the best Ph.D. Thesis in the Department of Electrical Communication Engineering, Indian Institute of Science, for the year 2006-2007. He is the recipient of the Visiting Research Fellowship at Jawaharlal Nehru Centre for Advanced Scientific Research (JNCASR), Bangalore. He has received the ISA Technolnventor Award in 2008 for his outstanding research contribution, from India Semiconductor Association (ISA).

He is a Fellow of Institution of Engineers - India (IEI), Member of The Institute of Electrical and Electronics Engineers (IEEE), Member of Institution of Electronics and Telecommunication Engineers (IETE), and Life Member of Indian Society of Technical Education (ISTE).

E-mail: bp_harish@yahoo.com

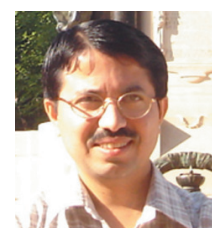

Navakanta Bhat received his B.E. in Electronics and Communication from University of Mysore in 1989, M.Tech. in Microelectronics from I.I.T. Bombay in 1992 and Ph.D. in Electrical Engineering from Stanford University, Stanford, CA in 1996. Then he worked at Motorola's Networking and Computing Systems Group in Austin, TX until 1999. At Motorola, he worked on logic technology development and he was responsible for developing high performance transistor design and dual gate oxide technology. He joined the Indian Institute of Science, Bangalore in 1999 where he is currently a Professor in the Centre for Nano Science and Engineering and Electrical Communication Engineering department. His current research is focused Nano-CMOS technology and Integrated CMOS-MEMS sensors. The work spans the domains of process technology, device design, circuit design and modeling. He is involved in setting up the Centre of excellence in Nanoelectronics at IISc. He has about 150 research publications in international journals and conferences and 5 US patents to his credit.

He has received the Young Engineer Award (2003) from the Indian National Academy of Engineering, Swarnajayanti fellowship (2005) from the Department of Science and Technology, Govt. of India and Prof. Satish Dhavan award (2005) from the Govt. of Karnataka. He is also the recipient of IBM Faculty award 2007 and Outstanding Research Investigator award (2010) from DAE.

He was the founding chair of the IEEE Electron Devices and Solid-State Circuits society, Bangalore chapter which was recognized as the Outstanding Chapter of the Year by the IEEE SSC society (2003) and IEEE EDS society (2005). He has been on the program committees of several international conferences. He was the technical program chair for the International Conference on VLSI design and Embedded Systems (2007). He was a Distinguished Lecturer of the IEEE Electron Devices Society. He is the Chairman of the Human Resource Development and Infrastructure committee of the National Program on Micro and Smart Systems.

E-mail: navakant@ece.iisc.ernet. 